\title{
Postoperative outcomes following rehabilitation in patients with left ventricular assist devices
}

\author{
Massimiliano Polastri' ${ }^{1}$, Silvia Boschi ${ }^{2}$, Giorgia Brillanti ${ }^{3}$, Sofia Martin-Suarez ${ }^{4}$, Marco Masetti², \\ Luciano Potena ${ }^{2}$, Antonio Loforte ${ }^{4}$ \\ ${ }^{1}$ Department of Continuity of Care and Disability, Physical Medicine and Rehabilitation, St. Orsola University \\ Hospital, Bologna; ${ }^{2}$ Heart Failure and Transplant Program, St. Orsola University Hospital, Bologna; ${ }^{3}$ Department of \\ Medical and Surgical Science, DIMEC, University of Bologna; ${ }^{4}$ Department of Cardiac-Thoracic-Vascular Diseases, \\ Cardiac Surgery and Transplantation, St. Orsola University Hospital, Bologna, Italy
}

\begin{abstract}
Postoperative rehabilitation is a cornerstone of the recovery pathway following left ventricular assist device implantation (LVAD), and patients are expected to conduct an autonomous life thanks to improved technology and increased knowledge of
\end{abstract}

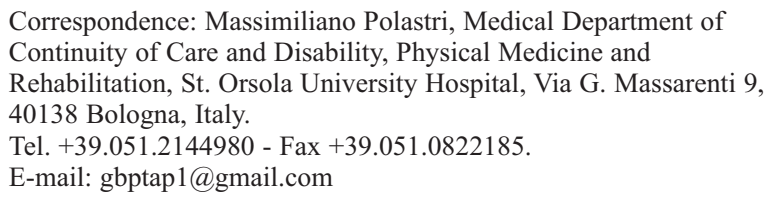

Key words: Activities of daily living; disability evaluation; heart-assist devices; outcomes assessment; physiotherapy; quality of life; rehabilitation; 6-Minute Walk Test.

Conflict of interest: The authors have no conflict of interest to declare.

Funding: None.

Contributions: All the authors made a substantive intellectual contribution, performed part of the experiments. All the authors have read and approved the final version of the manuscript and agreed to be accountable for all aspects of the work.

Availability of data and materials: The datasets used and/or analyzed during the current study are available from the corresponding author on reasonable request.

Ethics approval and consent to participate: Not applicable.

Conference presentation: Massimiliano Polastri presented a version of this article at the ISMCS 2019, $27^{\text {th }}$ Annual Meeting of the International Society for Mechanical Circulatory Support, held October 21-23, 2019, in Bologna, Italy.

Received for publication: 12 February 2020.

Accepted for publication: 9 April 2020.

${ }^{\circ}$ Copyright: the Author(s), 2020

Licensee PAGEPress, Italy

Monaldi Archives for Chest Disease 2020; 90:1249

doi: 10.4081/monaldi.2020.1249

This article is distributed under the terms of the Creative Commons Attribution Noncommercial License (by-nc 4.0) which permits any noncommercial use, distribution, and reproduction in any medium, provided the original author(s) and source are credited. mechanical circulatory support. The primary purpose of the present study was to quantify clinical changes related to rehabilitation, in patients with LVAD: functional capacity, disability, and quality of life were identified as reliable outcomes to detect such changes.

The current study was a scoping review conducted searching three primary databases, namely PubMed, Scopus, and Cochrane Library, from their inception until January 2020.

After the selection process was completed, 12 citations were included in the present study. Three hundred eight three patients were included in the current analysis. Functional capacity, disability, and quality of life were investigated in 157, 215, 18 patients, respectively. Significant differences were found before and after rehabilitation. The mean walked distance at 6-Minute Walk Test improved from $319 \pm 96$ to $412.8 \pm 86.2$ metres ( $<<0.001$ ), the mean score of the Functional Independence Measure from $68.4 \pm 11.8$ to $92.5 \pm 10.8$ points $(\mathrm{p}<0.001)$, the mean score of the Short Form-36 physical component from $32.7 \pm 29.9$ to $55.5 \pm 24.7$ points $(p=0.009)$ and the mental component from $55.8 \pm 19.8$ to $75.4 \pm 21.4$ points $(\mathrm{p}=0.002)$. Postoperative rehabilitation is effective at improving functional capacity, disability, and quality of life in patients with left ventricular assist device; all these three domains are particularly expressive of the entity of patients' functional recovery.

\section{Introduction}

The surgical treatment options for adults living with heart failure are increasingly becoming more common - due to the rising percentage of patients refractory to medical management improving survival rates in those subjects who are not candidates for heart transplantation [1]. Left ventricular assist device (LVAD) implantation has four primary indications, i) bridge to transplantation, ii) destination therapy (lifelong support), iii) bridge to myocardial recovery, iv) bridge to candidacy (temporary support) [2]. Postoperative rehabilitation is a cornerstone of the pathway of care contributing to improving functional capacity and reducing readmission rates following implantation [3]. Patients with LVAD can return to their daily activities after surgery [4]. Typically, postoperative rehabilitation in patients with LVAD can be divided into several steps from the acute phase to hospital discharge [5]. The physiotherapeutic treatment takes place at every stage during the postoperative recovery commencing in the intensive care unit (ICU), as soon as the patient is awake [6]. In the early period immediately after implantation, the rehabilitative goals are mainly 
directed to treat/prevent pulmonary complications; the ICU stay is characterised by the execution of respiratory exercises and in-bed positioning. Following ICU discharge, patients are usually subjected to motor recovery activities continuing respiratory therapy, as needed. In a more advanced phase of the postoperative timeframe, patients complete motor recovery and physical reconditioning, and starting self-administered exercise and becoming more socially active [5]. Significant complications of rehabilitative interest are primarily represented by stroke and respiratory failure [7]. Although several studies have been published discussing in detail rehabilitation in LVAD patients, to date, there is no available data defining cut-off values related to rehabilitative outcomes in such a population.

The primary purpose of the present study was to quantify clinical changes related to rehabilitation in patients with LVAD. To this end, the 6-Minute Walk Test (6MWT) for functional capacity, Functional Independence Measure (FIM) for disability, and the Short Form-36 (SF-36) for the quality of life were identified as reliable tools to detect such changes. The secondary aim of the study was to establish cut-off values for the variables investigated, considering the existing literature.

\section{Materials and Methods}

\section{Study design}

The current study was a scoping review [8] conducted by searching three primary databases, namely Cochrane Library, Scopus, and PubMed; the search went through the selected databases from their inception until January 2020. The search was done in the following fields; PubMed (all), Scopus (title, abstract, keywords), Cochrane Library (title, abstract, keywords).

\section{Search strategy}

Each database was searched using three Medical Subject Headings (MeSH) keywords; 1) LVAD, 2) physiotherapy and 3) rehabilitation. The MeSH terms were matched using the Boolean operator AND. After that, two search strings were built to search databases; "LVAD AND rehabilitation" and "LVAD AND physiotherapy". Studies retrieved were evaluated by two independent reviewers who have compared and agreed on the results; the selection process was completed in February 2020.

\section{Inclusion criteria}

The present study included adult patients ( $>18$ yrs) with no restrictions on gender, citations describing postoperative rehabilitation in LVAD patients with related outcome measures, and studies conducted in all settings (acute, sub-acute, long term care) with no restrictions regarding publication date. For the current research, the 6MWT, the FIM and the SF-36 were used to assess outcomes related to rehabilitation in the fields of functional capacity, disability, and quality of life, respectively.

\section{Exclusion criteria}

Paediatrics patients $(<18 \mathrm{yrs})$ were not included as well as those citations such as abstracts; conference proceedings; editorials; case reports; letters to the editor; or written in languages other than English, Spanish, French, Italian; investigating outcome measures not related to the postoperative rehabilitation. Citations reporting measurements tools other than 6MWT, FIM, and SF-36 were also excluded from the present analysis. Blood samples and chemistry tests on urine were not considered a measure of outcome for the present study as well as all types of imaging, biomarkers related to an organ function, survival rates, cardiopulmonary exercise test, spirometric analysis; length of hospital stay was not considered an outcome. Thus, all citations, as mentioned above, were not regarded as suitable for inclusion.

\section{Data analysis}

Each outcome measure was studied through meta-analytic methods and forest plot graphs. For each study, data have been expressed as mean and standard deviation. We used the standardised mean difference (SMD) for measurement of the effect (difference in means between before and after rehabilitation) [9]. For each outcome, a figure with graphs is presented: a forest plot combines the mean control values with $95 \%$ confidence intervals in every study (effect size). We explored heterogeneity across studies using the I-squared index. The meta-analyses were performed with both the Inverse Variance method (fixed effect) and the DerSimonian-Laird method (random effect); the Cochrane guidelines state that an I-squared value less than $40 \%$ would mean that the heterogeneity across studies might be not essential [10]. In forest plots, both fixed and random effect methods have been reported. All results are reported with $95 \%$ confidence intervals. A pvalue $<0.05$ was considered to indicate statistical significance. Statistical analyses were performed using Stata version $12 \mathrm{SE}$ (Stata Corp., College Station, TX, USA).

\section{Results}

The search returned a total of 321 citations, and after duplicates removal, 211 documents were assessed for eligibility. At the end of the selection process, 12 articles were retrieved for final analysis: nine were observational studies [3,11-19], while three were experimental trials $[15,20,21]$. A total of 383 patients (mostly males, as shown in Table 1) aged 59.2 \pm 12.3 years were included in the final analysis (Figure 1); they were subjected to different types of rehabilitation with diverse intensity, frequency, and duration (Table 1).

Functional capacity using the 6MWT was investigated in 157 ( $41 \%$ ) out of 383 patients, aged $54.6 \pm 12.4$ years, included from six studies; in that series, patients increased the mean walked distance after rehabilitation (Table 2).

Disability using the FIM was investigated in 215 (56\%) out of 383 patients, aged $63.3 \pm 10.6$ years, gathered from five studies; the FIM score improved after rehabilitation was completed (Table 2).

Quality of life using the SF-36 was investigated in $18(5 \%)$ patients out of 383 , aged $46.7 \pm 13.9$ years, gathered from two studies; either the physical and the mental component scores were analysed (Table 2).

Significant differences before and after rehabilitation were detected for 6MWT, FIM, and SF-36 (Table 2); the outcomes in all the domains investigated in the current analysis improved postoperatively (Figures 2-4). As previously highlighted, SMD has been used to detect changes before and after rehabilitation (Figures 3 and 4); in this regard, an SMD of 0 means that rehabilitation has no effect on the investigated domains. SMD greater than 0 indicates the degree to which rehabilitation is effective [9].

Regarding the treatment modalities, they were heterogeneous and different timeframe have been adopted across the studies, as shown in Table 1. Furthermore, there was considerable heterogeneity regarding the initiation of treatment that commenced ranging 
Table 1. Included studies $(n=12)$.

\begin{tabular}{|c|c|c|c|c|}
\hline Authors(year) [Ref.] & $\begin{array}{l}\text { LVAD } \\
\text { patients (n) } \\
\text { \{n of } M\}\end{array}$ & Intervention & Veasures & Main findings \\
\hline Racca et al. (2018) [11] & $(46)\{41 \mathrm{M}\}$ & $\begin{array}{l}\text { Patients were enrolled in a rehabilitation } \\
\text { programme (at least } 3 \text { weeks duration) } \\
42 \pm 44 \text { days after the operation. It comprised } \\
\text { respiratory exercises, endurance training, } \\
\text { walking or cycling, and limbs/trunk exercises. }\end{array}$ & 6MWT & $\begin{array}{l}\text { 6MWD: was measured at the entry of the study } \\
\text { and at discharge. The distance walked increased } \\
\text { by } 129 \pm 114 \text { metres after rehabilitation. }\end{array}$ \\
\hline Schmidt et al. (2018) [12] & (68) $\{59 \mathrm{M}\}$ & $\begin{array}{l}\text { Patients were enrolled in a rehabilitation } \\
\text { programme (at least } 3 \text { weeks duration) } \\
32 \pm 14.8 \text { days after implantation. The programme } \\
\text { included resistance exercise particularly focused } \\
\text { on lower extremities using exercise machines or } \\
\text { elastic bands. Endurance training was also } \\
\text { executed on a bicycle ergometer. }\end{array}$ & $6 \mathrm{MWT}$ & $\begin{array}{l}\text { 6MWD: was measured at the beginning and at the } \\
\text { end of rehabilitation. The distance walked } \\
\text { increased by } 80.3 \pm 82.5 \text { metres. }\end{array}$ \\
\hline Marko et al. (2017) [16] & $(10)\{-\}$ & $\begin{array}{l}\text { Aerobic (bicycle ergometer) and strength } \\
\text { training (lower extremities) limiting the exercise } \\
\text { exertion to somewhat hard in the Borg scale. } \\
\text { The programme included also coordination and } \\
\text { balance training, and walking. }\end{array}$ & $6 \mathrm{MWT}$ & $\begin{array}{l}\text { 6MWD: was measured in } 10 \text { patients who } \\
\text { completed a second rehabilitation programme. } \\
\text { The distance walked increased by } 59 \pm 7 \text { metres } \\
\text { after rehabilitation. }\end{array}$ \\
\hline
\end{tabular}

\begin{tabular}{|c|c|c|c|c|}
\hline Yost et al. (2017) [3] & $(90)\{75 \mathrm{M}\}$ & $\begin{array}{l}\text { Three hours therapy daily including hand } \\
\text { dexterity and grip strength. The programme also } \\
\text { included transfers, gait training, and stairs. } \\
\text { Patients were admitted to the rehabilitation } \\
\text { programme after } 32.1 \pm 20.7 \text { days. }\end{array}$ & FIM & $\begin{array}{l}\text { FIM: score improved by } 28.4 \pm 12.3 \text { points after } \\
\text { inpatient rehabilitation. }\end{array}$ \\
\hline Kerrigan et al. (2014) [15] & $(16)\{-\}$ & $\begin{array}{l}\text { Supervised exercise } 3 \text { sessions per week for } \\
6 \text { weeks ( } 18 \text { sessions) including a } 5 \text {-min warm-up, } \\
\text { treadmill and stationary cycle or arm ergometer }\end{array}$ & 6MWT & $\begin{array}{l}\text { 6MWT: baseline ( } 350.1 \pm 64.7 \text { metres); follow-up } \\
(402.4 \pm 89.3 \text { metres). }\end{array}$ \\
\hline
\end{tabular}

\begin{tabular}{|c|c|c|c|c|}
\hline Alsara et al. (2014) [17] & $(47)\{40 \mathrm{M}\}$ & $\begin{array}{l}\text { Individual plan of care addressing impairments } \\
\text { and activity limitations. The inpatient programme } \\
\text { lasted } 6.6 \pm 3.9 \text { days. }\end{array}$ & FIM & $\begin{array}{l}\text { FIM score improved significantly ( } 77.1 \text { vs } 95.2 \\
\text { points). }\end{array}$ \\
\hline Chu et al. (2014) [18] & $(47)\{-\}$ & Inpatient rehabilitation lasting $20.4 \pm 10.9$ days. & FIM & $\begin{array}{l}\text { FIM score: mean difference before/after } 23.4 \\
\text { points. }\end{array}$ \\
\hline English et al. (2013) [19] & $(20)\{-\}$ & Inpatient rehabilitation lasting $11.6 \pm 3.9$ days. & FIM & FIM: mean score improved by 22.1 points. \\
\hline Karapolat et al. (2013) [14] & $(11)\{9 \mathrm{M}\}$ & $\begin{array}{l}\text { Supervised CR consisting of } 90 \text {-min sessions, } \\
3 \text { times a week, for } 8 \text { weeks (aerobic, flexibility, } \\
\text { strengthening, breathing, and relaxation } \\
\text { exercises). }\end{array}$ & SF-36 & $\begin{array}{l}\text { SF-36: significant improvements were registered } \\
\text { after treatment in the following items: physical } \\
\text { role, pain, vitality, emotional role, and mental } \\
\text { health. }\end{array}$ \\
\hline
\end{tabular}

\begin{tabular}{|c|c|c|c|c|}
\hline Nguyen et al. (2013) [13] & $(11)\{8 \mathrm{M}\}$ & $\begin{array}{l}\text { Standard inpatient rehabilitation: } 3 \mathrm{~h} \text { per day of } \\
\text { comprehensive physical and occupational therapy. } \\
\text { The mean duration was } 17.5 \pm 8.9 \text { days; patients } \\
\text { were admitted to the programme } 48.6 \pm 18.2 \text { days } \\
\text { after implantation. }\end{array}$ & FIM & $\begin{array}{l}\text { FIM gain was } 28.6 \pm 10.2 \text { points after treatment } \\
\text { inpatient rehabilitation. }\end{array}$ \\
\hline Hayes et al. (2012) [21] & $(7)\{6 \mathrm{M}\}$ & $\begin{array}{l}\text { Walking maintaining an intensity of somewhat } \\
\text { hard Borg scale. Exercise training: } 1 \mathrm{~h}, 3 \text { days } \\
\text { weekly for } 8 \text { weeks. Training consisted of } 15 \\
\text { minutes of stationary cycling and } 15 \text { minutes of } \\
\text { treadmill. In addition, strength training was }\end{array}$ & $\begin{array}{l}\text { SF-36 } \\
6 \mathrm{MWT}\end{array}$ & $\begin{array}{l}\text { SF-36: the total score improved significantly after } \\
\text { treatment. } 6 \mathrm{MWT} \text { : was measured at the } \\
\text { beginning and at the end of rehabilitation. } \\
\text { The distance walked increased from } \\
351 \pm 77 \text { to } 531 \pm 131 \text { metres. }\end{array}$ \\
\hline
\end{tabular}
implemented by 3 upper limb and 3 lower limb exercises using weight machine (2 sets of 10 repetitions). Patients attended $21.3 \pm 1.5$ exercises sessions.

\begin{tabular}{|c|c|c|c|c|}
\hline Laoutaris et al. (2011) [20] & $(10)\{10 \mathrm{M}\}$ & $\begin{array}{l}\text { Inpatient rehabilitation programme } \\
\text { (10 weeks duration) including } 30-45 \text { minutes } \\
\text { walking, respiratory exercises (IMT), early } \\
\text { mobilisation, progressive aerobic and } \\
\text { resistance training. }\end{array}$ & 6MWT & $\begin{array}{l}\text { 6MWT: pre-training ( } 462 \pm 88 \text { metres), } \\
\text { post-training ( } 527 \pm 76 \text { metres). }\end{array}$ \\
\hline
\end{tabular}


from 1 to six months after surgery. Although in several included studies the point in time when rehabilitation began - after LVAD implantation - was specified as shown in Table 1 [3,11-13], in others, this variable was not available preventing us from providing more details.

\section{Discussion}

In the last decade, an increasing interest has been mounted on the effects and techniques of postoperative rehabilitation in LVAD patients. As a matter of fact, LVADs are increasingly used as destination therapy in patients with end-stage heart failure. With the current study, we found that 6MWT, FIM and SF-36 were the most used evaluation tools to detect clinical changes related to rehabilitation in such a class of patients. Nevertheless, in conducting our research, we observed that other variables are attracting increasing interests among authors, such as pulmonary function tests $[14,20]$ and strength tests (handgrip and quadriceps strength) [15,22,23]. It should be argued that such a new trend will be better developed in the future expanding boundaries of knowledge in these specific topics; however, we believe that the analysis of more inclusive outcomes - as carried out in the current study - represent today a starting point to pave the way for further investigation. We were able to define specific values for each of the outcomes we investigated and, for the first time in literature, we can have these data available to compare our results with daily clinical practice. Indeed, 6MWT, FIM and SF-36 are particularly expressive of the entity of patients' functional recovery, following LVAD implantation.

Table 2. Differences before and after rehabilitation, and cut-off values of each domain.

\begin{tabular}{|c|c|c|c|c|c|}
\hline Domains & $\mathrm{N}$ of studies & $\mathrm{N}$ of patients & $\begin{array}{c}\text { Variables } \\
\text { Before rehabilitation } \\
(\text { mean } \pm \text { SD })\end{array}$ & $\begin{array}{l}\text { After rehabilitation } \\
\quad(\text { mean } \pm \text { SD })\end{array}$ & p \\
\hline Functional capacity (6MWT), (m) & 6 & 157 & $319.0 \pm 96.0$ & $412.8 \pm 86.2$ & $<0.001^{*}$ \\
\hline Disability (FIM), (pts) & 5 & 215 & $68.4 \pm 11.8$ & $92.5 \pm 10.8$ & $<0.001^{*}$ \\
\hline Quality of life (SF-36), (pts) & 2 & 18 & - & - & - \\
\hline Physical component score & - & - & $32.7 \pm 29.9$ & $55.5 \pm 24.7$ & $0.009 *$ \\
\hline Mental component score & - & $-\quad 1 \quad x-1$ & $55.8 \pm 19.8$ & $75.4 \pm 21.4$ & $0.002 *$ \\
\hline
\end{tabular}

SD, standard deviation; 6MWT, 6-Minute Walk Test; m, metres; FIM, Functional Independence Measure; pts, points; SF-36, Short Form-36; ${ }^{*} \mathrm{p}<0.05$ was considered to indicate statistical significance.

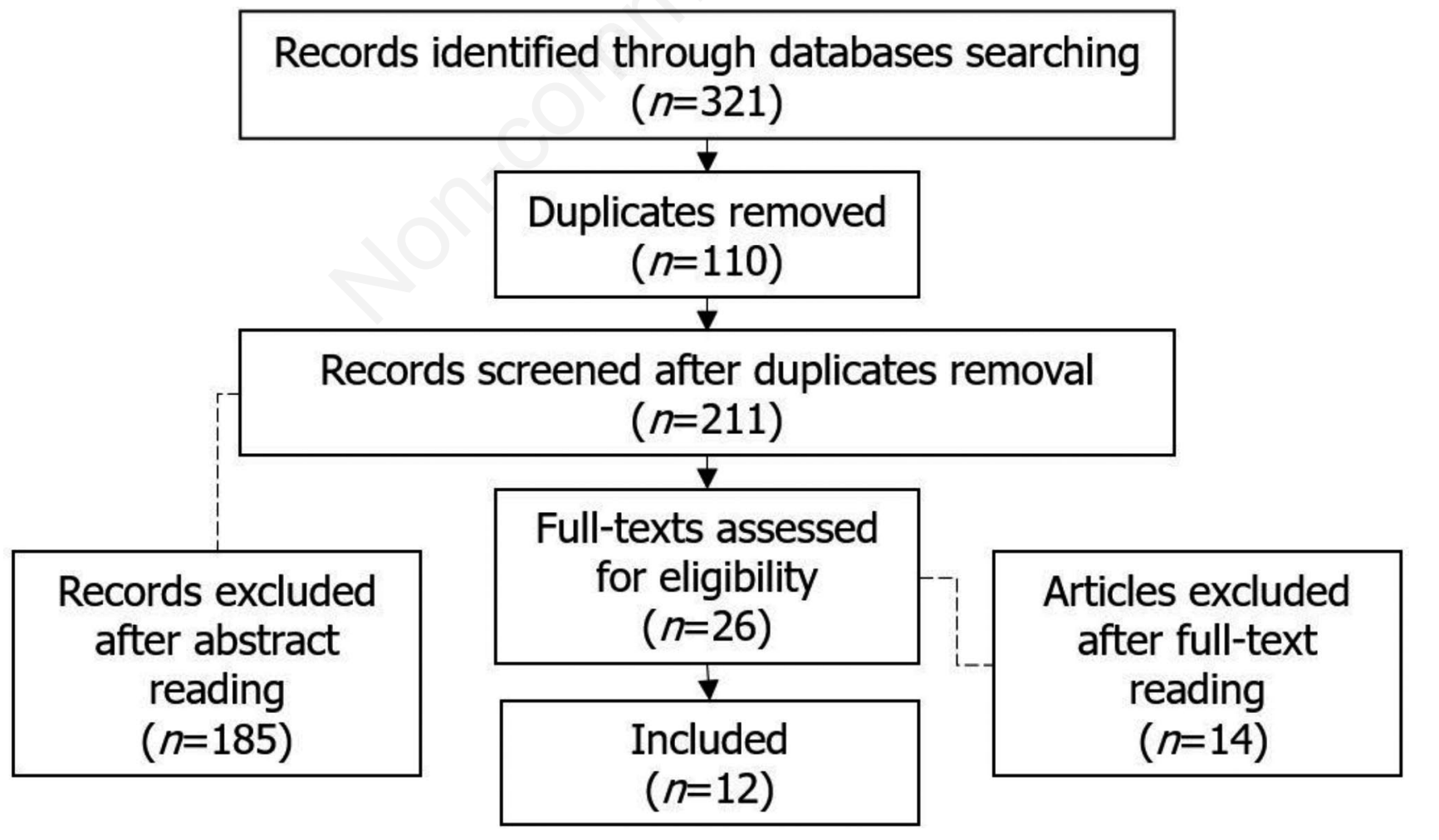

Figure 1. Search flow. 


\section{Outcome measures}

Functional capacity can be defined as the person's ability to perform activities that require physical exertion; the integrity of the cardiovascular, respiratory and skeletal muscle systems is essential to determine individual functional capacity [24]. The $6 \mathrm{MWT}$ is a test to objectify functional exercise capacity; it evaluates the global responses of all body systems involved during exercise. The $6 \mathrm{MWT}$ is widely used for measuring the response to therapeutic interventions for pulmonary and cardiac diseases [25]. The
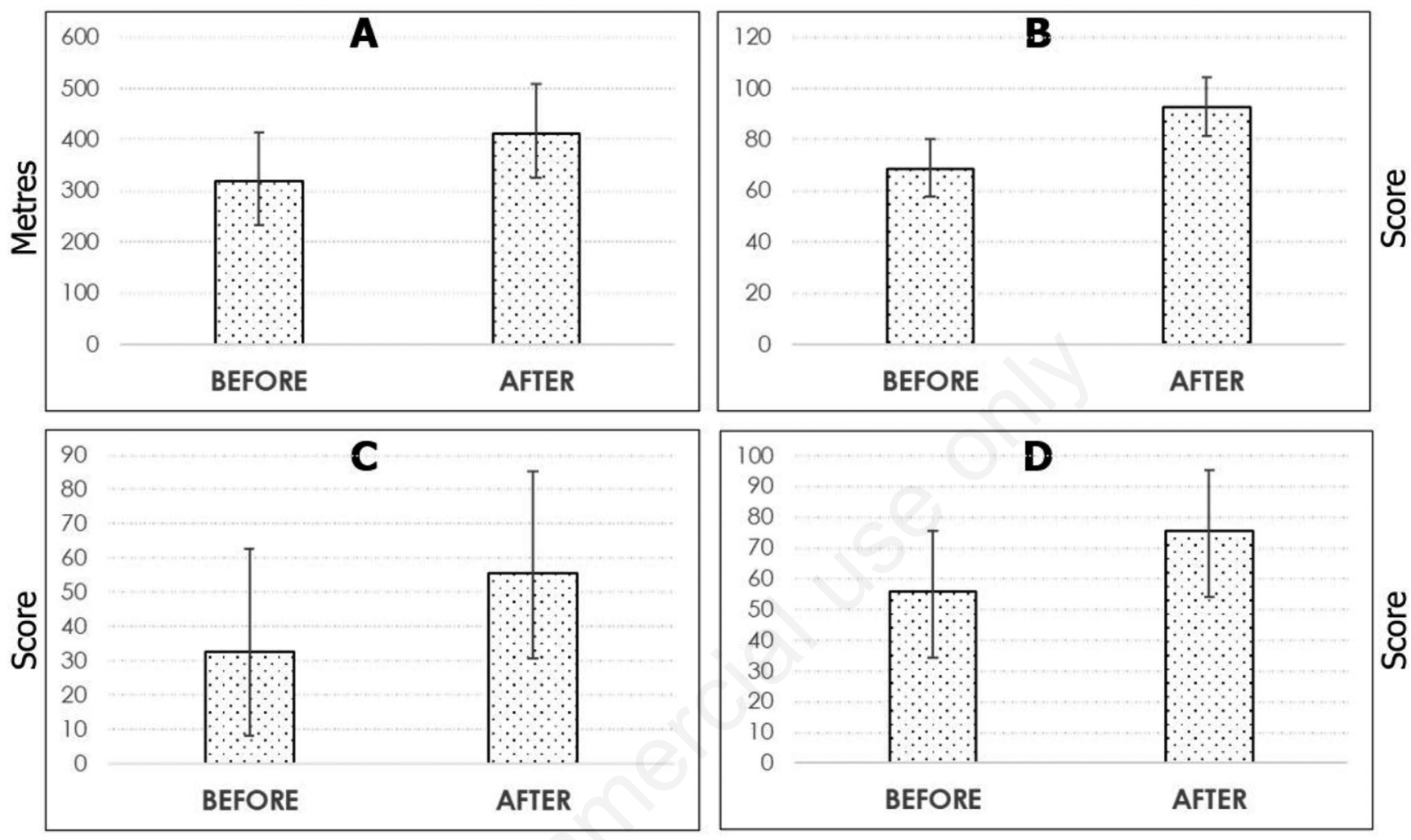

Figure 2. Differences before and after rehabilitation, in each domain. A) 6MWT test. B) FIM test. C) SF-36 physical component score. D) SF-36 mental component score. 6MWT, 6-Minute Walk Test; FIM, Functional Independence Measure; SF-36, Short Form-36.
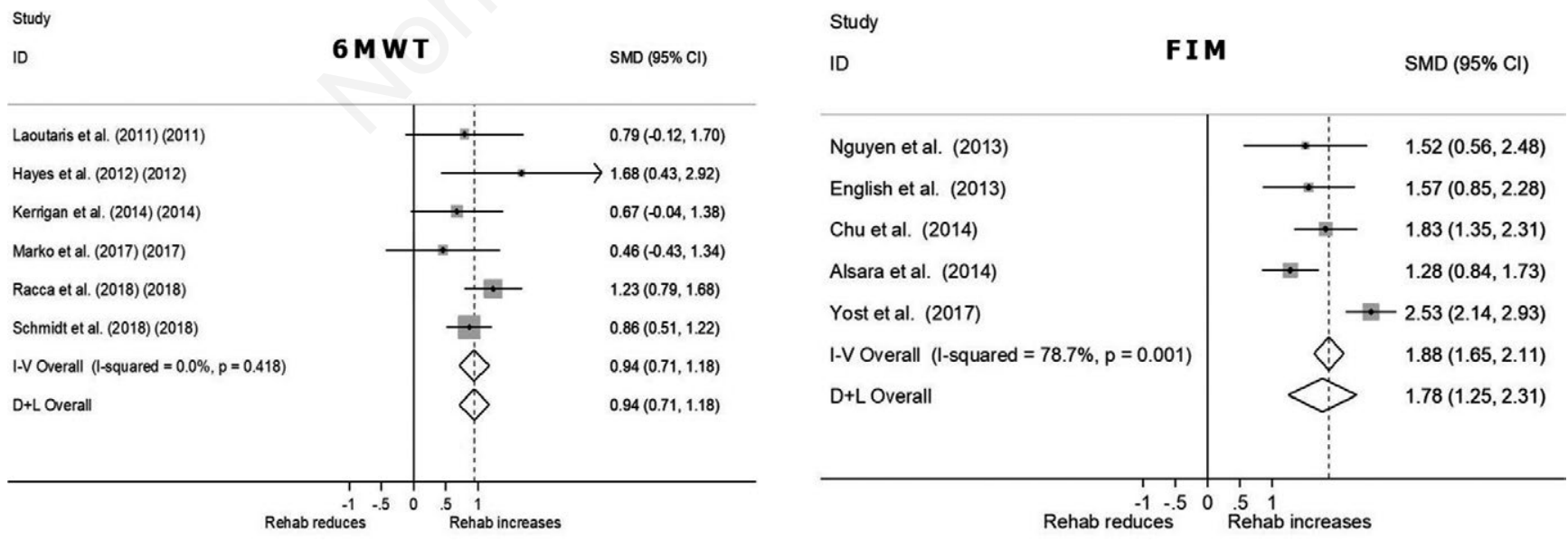

Figure 3. Forest plot of effect size estimates on rehabilitation: functional capacity (6MWT) and disability (FIM) domains. Squares represent the effect size estimate and horizontal lines represent the confidence intervals for each study. The diamonds represent the estimates of the overall effect size (in both fixed and random effects models). The vertical line represents the null hypothesis (SMD=0), whereas the vertical dotted line represents the overall mean difference from all studies. A positive effect size is identifying postoperative rehabilitation effectiveness. 6MWT, 6-Minute Walk Test; CI, confidence interval; SMD, standardised mean difference; FIM, Functional Independence Measure. 
object of the test is to walk as far as possible for six minutes. Patients are permitted to slow down, to stop or to rest as necessary during its execution.

Disability is a complex phenomenon, reflecting the interaction between features of a person's body and features of the society in which he or she lives [26]. The FIM scale is used to determine the degree of disability that patients experience and the signs of progress that they make throughout rehabilitation [27]. FIM is comprised of 18 items grouped into two subscales; motor (13 items) and cognition (5 items). Each item is scored in a 7-point ordinal scale (min 1-max 7), the total score of the FIM ranges from 18 to 126; the higher the score, the more independent the patients is. The overall rating of the motor subscale ranges from 13 to 91 points while that of the cognition subscale ranges from 5 to 35 points.

Quality of life is an individual's perception of their position in living in the context of the culture and value systems in which they live and in relation with their goals, expectations, standards and concerns [28]. The SF-36 is a health questionnaire which includes one multi-item scale that assesses eight health concepts: 1) limitations in physical activities because of health problems; 2) limitations in social activities because of physical or emotional problems; 3) limitations in usual role activities because of physical health problems; 4) bodily pain; 5) general mental health; 6) limitations in usual role activities because of emotional problems; 7) vitality; and 8) general health perceptions [29]. The score of the SF-36 ranges from 0 to 100 , with a higher rating indicating better health; low scores in the physical function scale are the expression of limitations in physical activities including bathing or dressing. In the same way, low scores on social functioning are typical in those patients who experience difficulties in regular social activities due to the physical and emotional health problems [30].

As we have previously highlighted, LAVDs are increasingly used as destination therapy due to the shortage of donors, reinforcing the need to detect clinical changes in a multifaceted clinical context rather than in some specific issues. However, the possibility to gather additional details regarding specific physical outcomes (i.e., pulmonary function, body strength) can definitively contribute to planning a more efficacious and reliable postopera-

ID

$$
\text { SF-36 PCS }
$$

$\operatorname{SMD}(95 \% \mathrm{Cl})$

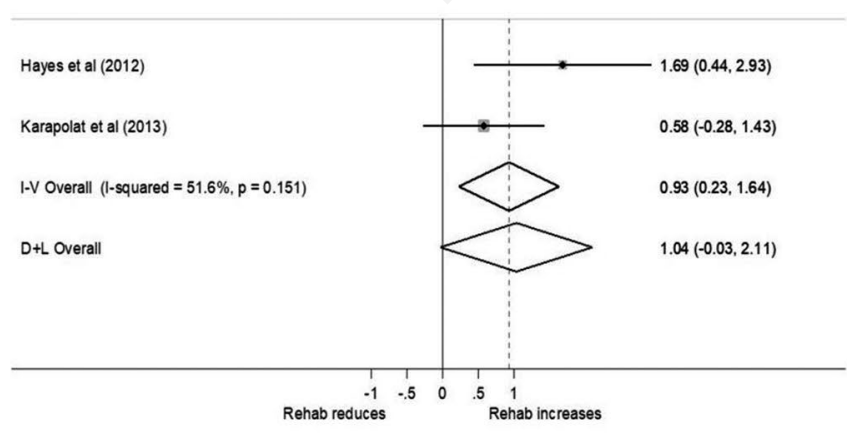

tive recovery pathway tailoring the rehabilitative intervention on singular patients' characteristics and needs.

Although the current analysis includes different types of outcomes, each contributed to identifying changes related to rehabilitation, postoperatively. In planning postoperative care for patients with LVAD, the results of our study can assist in optimising the physiotherapeutic intervention, definitively.

It should be noted that most of the studies had no control group. This was probably due to the fact each study aimed at detecting rehabilitation effects instead of the efficacy of a given rehabilitative treatment/modality over another. At the same time, we should not forget the population of LVAD patients is still representing a narrow context if we compare it with others rehabilitative cohorts (e.g., chronic obstructive pulmonary disease, orthopaedic, musculoskeletal patients). In addition, it was not possible to gather further information regarding the presence of adults with congenital heart disease who should be considered paediatrics; nonetheless, lack of data about this variable would not alter the results of our analysis.

\section{Limitations}

The current study bears several limitations; firstly, it was not possible to identify a standardised rehabilitative treatment, as in each study the intervention was carried out with different modalities and commenced at different points of time, postoperatively. In this regard, from the available literature, it was not possible to precisely identify when patients started rehabilitation after implantation; high variability of this data did not allow to stratify the analysis considering this variable. Another limitation could be recognised in the absence of previously published cut-off values for the variables we investigated to compare our findings; at the same time, this represents the strength of our analysis that provides detailed data to be used for stratifying functional capacity, disability, and quality of life in such a patient population. Furthermore, when analysing figures regarding the SF-36, only 18 patients were included; on the other hand, this was the population available. In this regard, we guess this is not a limitation of the study; instead, more researches are needed in that field to enlarge such a specific cohort.
Study

ID

SF-36 MCS

$\operatorname{SMD}(95 \% \mathrm{Cl})$

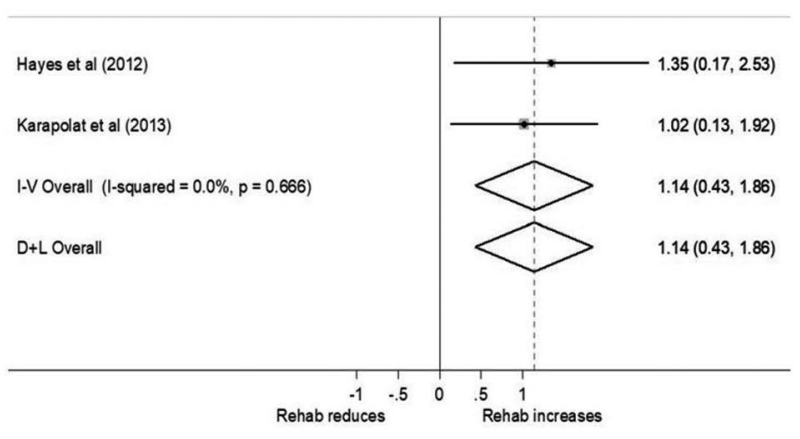

Figure 4. Forest plot of effect size estimates on rehabilitation: quality of life. Squares represent the effect size estimate and horizontal lines represent the confidence intervals for each study. The diamonds represent the estimates of the overall effect size (in both fixed and random effects models). The vertical line represents the null hypothesis (SMD=0), whereas the vertical dotted line represents the overall mean difference from all studies. A positive effect size is identifying postoperative rehabilitation effectiveness. SF-36 PCS, Short Form36 Physical Component Score; CI, confidence interval; SMD, standardised mean difference; SF-36 MCS, Short Form-36 Mental Component Score. 
Eventually, although we summarised in Table 1 the characteristics of the rehabilitative interventions, we did not provide a detailed description of the treatment. In this regard, we should not forget the present study is a scoping review conducted to identify critical characteristics of outcomes rather than physiotherapeutic procedures: so, we guess the analysis of the rehabilitative intervention can be worthy of a different and separate investigation. Nevertheless, a synthesis of the rehabilitative techniques has been provided in Table 1.

\section{Conclusions}

Postoperative rehabilitation is a cornerstone of the recovery pathway following LVAD implantation and patients are expected to conduct an autonomous life thanks to improved technology and increased knowledge of LVADs. Evidence indicates that rehabilitation has a positive effect on functional capacity, disability, and quality of life in patients with LVAD.

\section{References}

1. Eickmeyer SM, Barker KD, Sayyad A, Rydberg L. The rehabilitation of patients with advanced heart failure after left ventricular assist device placement: a narrative review. PM R 2019;11:64-75.

2. Boruah P, Saqib N, Barooah J, et al. Left ventricular assist device: what the internist needs to know. A review of the literature. Cureus 2019;11:e4399.

3. Yost G, Coyle L, Milkevitch K, et al. Efficacy of inpatient rehabilitation after left ventricular assist device implantation. PM R 2017;9:40-5.

4. Hanke JS, Riebandt J, Wahabzada M, et al. Driving after left ventricular assist device implantation. Artif Organs 2018;42:695-9.

5. Compostella L, Polastri M, Lamotte M, et al. Physiotherapy and rehabilitation management in adult LVAD patients. In: Montalto A, Loforte A, Musumeci F, Krabatsch T, Slaughter MS, editors. Mechanical circulatory support in end-stage heart failure. A practical manual. Cham: Springer; 2017. pp 403-20.

6. Polastri M, Zagnoni G, Loforte A. Basic movements for postoperative exercise in patients with left ventricular assist devices. Monaldi Arch Chest Dis 2019;89:995. doi: 10.4081/monaldi.2019.995.

7. Pinney SP, Anyanwu AC, Lala A, et al. Left ventricular assist devices for lifelong support. J Am Coll Cardiol 2017;69:2845-61.

8. Munn Z, Peters MDJ, Stern C, et al. Systematic review or scoping review? Guidance for authors when choosing between a systematic or scoping review approach. BMC Med Res Methodol 2018;18:143.

9. Faraone SV. Interpreting estimates of treatment effects: implications for managed care. P\&T 2008;33:700-11.

10. Higgins JPT, Green S. Cochrane handbook for systematic reviews on interventions, ver. 5.1.0, updated March 2011. The Cochrane Collaboration, 2011. Accessed on: 1 April 2020. Available from: http://handbook.cochrane.org

11. Racca V, Castiglioni P, Panzarino C, et al. Differences in biochemical markers between heart-transplanted and left ventricular assist device implanted patients, during cardiac rehabilitation. Sci Rep 2018;8:10819.

12. Schmidt T, Bjarnason-Wehrens B, Bartsch P, et al. Exercise capacity and functional performance in heart failure patients supported by a left ventricular assist device at discharge from inpatient rehabilitation. Artif Organs 2018;42:22-30.

13. Nguyen E, Stein J. Functional outcomes of adults with left ventricular assist devices receiving inpatient rehabilitation. PM R 2013;5:99-103.

14. Karapolat H, Engin C, Eroglu M, et al. Efficacy of the cardiac rehabilitation program in patients with end-stage heart failure, heart transplant patients, and left ventricular assist device recipients. Transplant Proc 2013;45:3381-5.

15. Kerrigan DJ, Williams CT, Ehrman JK, et al. Cardiac rehabilitation improves functional capacity and patient-reported health status in patients with continuous-flow left ventricular assist devices: the Rehab-VAD randomized controlled trial. JACC Heart Fail 2014;2:653-9.

16. Marko C, Xhelili E, Lackner T, et al. Exercise performance during the first two years after left ventricular assist device implantation. ASAIO J 2017;63:408-13.

17. Alsara O, Reeves RK, Pyfferoen MD, et al. Inpatient rehabilitation outcomes for patients receiving left ventricular assist device. Am J Med Phys Rehabil 2014;93:860-8.

18. Chu SK, McCormick Z, Hwang S, et al. Outcomes of acute inpatient rehabilitation of patients with left ventricular assist devices. PM R 2014;6:1008-12.

19. English ML, Speed J. Effectiveness of acute inpatient rehabilitation after left ventricular assist device placement. Am J Med Phys Rehabil 2013;92:621-6.

20. Laoutaris ID, Dritsas A, Adamopoulos S, et al. Benefits of physical training on exercise capacity, inspiratory muscle function, and quality of life in patients with ventricular assist devices long-term postimplantation. Eur J Cardiovasc Prev Rehabil 2011;18:33-40.

21. Hayes K, Leet AS, Bradley SJ, Holland AE. Effects of exercise training on exercise capacity and quality of life in patients with a left ventricular assist device: a preliminary randomized controlled trial. J Heart Lung Transplant 2012;31:729-34.

22. Ugata Y, Wada H, Sakakura K, et al. High-intensity interval training for severe left ventricular dysfunction treated with left ventricular assist device. Int Heart J 2018;59:216-9.

23. Amao R, Imamura T, Nakahara $Y$, et al. Reversible motor paralysis and early cardiac rehabilitation in patients with advanced heart failure receiving left ventricular assist device therapy. Int Heart J 2016;57:766-8.

24. Arena R, Cahalin LP, Borghi-Silva A, Phillips SA. Improving functional capacity in heart failure: the need for a multifaceted approach. Curr Opin Cardiol 2014;29:467-74.

25. ATS Committee on Proficiency Standards for Clinical Pulmonary Function Laboratories. ATS statement: guidelines for the six-minute walk test. Am J Respir Crit Care Med 2002;166:111-7

26. WHO. Health topics. Disabilities. Accessed on: 1 April 2020. Available from: https://www.who.int/topics/disabilities/en/

27. Granger CV, Hamilton BB, Linacre JM, et al. Performance profiles of the functional independence measure. Am J Phys Med Rehabil 1993;72:84-9.

28. 26. WHO. Health statistics and information systems. Measuring quality of life. Accessed on: 1 April 2020. Available from: https://www.who.int/healthinfo/survey/whoqol-qualityoflife/en/

29. Ware JE Jr, Sherbourne CD. The MOS 36-item short-form health survey (SF-36). I. Conceptual framework and item selection. Med Care 1992;30:473-83.

30. Busija L, Pausenberger E, Haines TP, et al. Adult measures of 
general health and health-related quality of life: Medical Outcomes Study Short Form 36-Item (SF-36) and Short Form 12-Item (SF-12) Health Surveys, Nottingham Health Profile (NHP), Sickness Impact Profile (SIP), Medical Outcomes
Study Short Form 6D (SF-6D), Health Utilities Index Mark 3 (HUI3), Quality of Well-Being Scale (QWB), and Assessment of Quality of Life (AQOL). Arthritis Care Res (Hoboken) 2011;63:S383-S412. 